\title{
EFEITO DE AGENTES GELEIFICANTES ALTERNATIVOS NO MEIO DE CULTURA NO CULTIVO IN VITRO DE ABACAXIZEIRO E BANANEIRA
}

\author{
Effect of alternative gelling agents in culture medium in the in vitro \\ cultivation of pineapple and banana
}

\author{
Frederico Henrique da Silva Costa ${ }^{1}$, Maria Aparecida Alves Pereira ${ }^{2}$, \\ Janiffe Peres de Oliveira ${ }^{2}$, Jonny Everson Scherwinski Pereira ${ }^{3}$
}

\begin{abstract}
RESUMO
Com este trabalho, objetivou-se avaliar a ação do ágar e sua substituição parcial e total pelo amido de mandioca na composição de meios de cultura de bananeira e abacaxizeiro. Gemas axilares de abacaxizeiro, cvs. Rio Branco e Quinari foram estabelecidas e avaliadas por quatro subcultivos quanto à multiplicação em meio de MS, suplementado com 2 mg.L. - $^{-1}$ de BAP e $0,25 \mathrm{mg} . \mathrm{L}^{-1}$ de ANA, e os seguintes tratamentos: $\mathrm{M}_{1}$ : ágar $\left(5 \mathrm{~g} \cdot \mathrm{L}^{-1}\right), \mathrm{M}_{2}$ : ágar $\left(2,5 \mathrm{~g} \cdot \mathrm{L}^{-1}\right)+$ fécula de mandioca $\left(60 \mathrm{~g} . \mathrm{L}^{-1}\right), \mathrm{M}_{3}$ : fécula de mandioca $\left(60 \mathrm{~g} . \mathrm{L}^{-1}\right)$, e $\mathrm{M}_{4}$ : ágar $\left(2,5 \mathrm{~g} . \mathrm{L}^{-1}\right)+$ fécula de mandioca $\left(30 \mathrm{~g} . \mathrm{L}^{-1}\right)$. Num segundo experimento, por trềs subcultivos sucessivos brotações de bananeira da cv. Grand Naine foram avaliadas quanto à multiplicação em meio de cultura

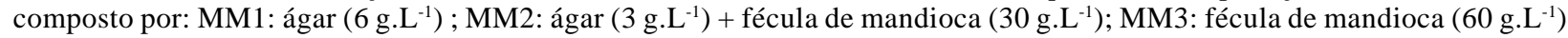
e; MM4: meio de consistência líquida estacionário. Estes meios foram suplementados com 0, 2, 4 e 6 mg.L - $^{-1}$ de BAP. Para o abacaxizeiro, verificou-se que a substituição total do ágar pela fécula proporcionou resultados similares aos obtidos com o tratamento com ágar. Na combinação ágar + fécula os resultados foram inferiores aos obtidos com os solidificantes usados isoladamente. Para a bananeira, o uso isolado ou combinado da fécula com ágar não proporcionou melhora nas taxas de multiplicação. Os melhores resultados foram obtidos em meio com ágar e $2 \mathrm{mg} . \mathrm{L}^{-1}$ de BAP. O cultivo em meio líquido apresentou o menor índice de multiplicação.
\end{abstract}

Termos para indexação: Musa sp., Ananas sp., micropropagação, amido de mandioca.

\begin{abstract}
The objective of this work was to test the agar action and its partial and total substitution for cassava starch as gelling agents in the culture media of banana and pineapple. Axillary buds of 'Rio Branco' and 'Quinari' cultivars were established and the multiplication rate evaluated by four subcultives in media with $2 \mathrm{mg} . \mathrm{L}^{-1} \mathrm{BAP}$ and $0,25 \mathrm{mg} . \mathrm{L}^{-1} \mathrm{NAA}$, with the following combination of gelling agents: M1: agar $\left(5\right.$ g. $\left.\mathrm{L}^{-1}\right), \mathrm{M} 2$ : agar $\left(2,5 \mathrm{~g} . \mathrm{L}^{-1}\right)+\operatorname{cassava} \operatorname{starch}\left(60 \mathrm{~g} . \mathrm{L}^{-1}\right)$, M3: cassava starch $\left(60 \mathrm{~g} . \mathrm{L}^{-1}\right)$, and M4: agar $\left(2,5\right.$ g. $\left.\mathrm{L}^{-1}\right)+$ cassava starch $\left(30\right.$ g. $\left.\mathrm{L}^{-1}\right)$. In a second experiment, for three successive subcultivation shoots of banana, 'Grand Naine' cultivar were evaluated in media composed with the following gelling treatments: MM1: agar $\left(6 \mathrm{~g} . \mathrm{L}^{-1}\right)$; MM2: agar (3 g.L. $\left.\mathrm{L}^{-1}\right)+$ cassava starch $\left(30 \mathrm{~g} . \mathrm{L}^{-1}\right)$; MM3: cassava starch $\left(60 \mathrm{~g} . \mathrm{L}^{-1}\right)$ and; MM4: stationary liquid medium. To these media were added $0,2,4$ and $6 \mathrm{mg} . \mathrm{L}^{-1} \mathrm{BA}$. To pineapple it was verified similar results when agar was completely substituted for cassava starch as gelling agent, but the combination agar + cassava starch provided the worse results when compared with gelling agents used separately. For banana shoots multiplication, the isolated or combined use of cassava starch did not improve the multiplication rates. The best results were obtained in medium with $2 \mathrm{mg} . \mathrm{L}^{-1} \mathrm{BA}$ and agar as gelling agent. The shoot cultivation in liquid medium presented the lowest multiplication index.
\end{abstract}

Index terms: Musa sp., Ananas sp., micropropagation, cassava starch.

(Recebido para publicação em 9 de março de 2006 e aprovado em 30 de agosto de 2006)

\section{INTRODUÇÃO}

A cultura de tecidos de plantas, também conhecida como cultivo in vitro ou micropropagação, vem se tornando uma técnica cada vez mais comum no mercado visando suprir a demanda de uma fruticultura cada vez mais tecnificada e com uma alta capacidade de multiplicação em grande escala de mudas livres de patógenos (MENDES et al., 1996). Dentre as vantagens da micropropagação deve-se ressaltar a propagação rápida mediante à indução de múltiplos brotos, resultando em material propagativo com potencial de produção contínua. No entanto, o sucesso na aplicação desta técnica depende de uma série de fatores que precisam ser controlados adequadamente durante o processo.

Para as culturas da banana e do abacaxi esta técnica tem sido rotineiramente utilizada para a produção de materiais propagativos isentos de patógenos, constituindo-se como uma etapa de grande importância no processo de

\footnotetext{
Mestrando do Curso de Fitotecnia do Departamento de Agricultura da Universidade Federal de Lavras/UFLA - Cx. P. 3037 - $37200-000$ - Lavras, MG fredericohenrique@yahoo.com.br

${ }^{2}$ Bolsistas PIBIC/CNPq, Laboratório de Morfogênese e Biologia Molecular. Embrapa Acre - Rio Branco, AC - janiffepoliveira@hotmail.com ${ }^{3}$ Pesquisador, Doutor, Embrapa Acre - Laboratório de Morfogênese e Biologia Molecular - Cx. P. 321 - 69908-970 - Rio Branco, AC - Bolsista em Produtividade do CNPq - jonny@cpafac.embrapa.br
} 
produção de matrizes de qualidade. Portanto, a otimização desta fase passa a ser um fator fundamental do processo de produção de material propagativo de alta qualidade fitossanitária e de baixos custos (GUERRA et al., 1999; PINHO, 2003).

Apesar de já ser bastante utilizada para inúmeras espécies de plantas e para diversos fins, o uso comercial da micropropagação e de seus produtos é ainda limitado, especialmente pelo elevado custo dos reagentes e equipamentos utilizados e pela relativa baixa eficiência no desenvolvimento e multiplicação de algumas espécies. Por isso, pesquisas vêm sendo realizadas com o objetivo de otimizar e desonerar os custos da técnica (PEREIRA et al., 1999; PEREIRA \& FORTES, 2003; PINHO, 2003). Na literatura existem referências sobre vários ensaios e muitos meios de cultura têm sido testados visando melhorar essas etapas. Contudo, os resultados são muitas vezes divergentes e nem sempre é possível a reprodução dos mesmos. Isto se deve, principalmente, ao fato de que a cultura de tecidos, como técnica de propagação vegetativa, necessita ser adaptada às necessidades das espécies e cultivares, pois estas diferem geneticamente entre si, podendo apresentar resultados diferentes sob as mesmas condições de cultivo (FORTES \& PEREIRA, 2001).

Outro fator a ser considerado é o estado físico dos meios de cultura. A maioria dos trabalhos com bananeira e abacaxizeiro in vitro baseia-se no uso de meios de cultura semi-sólidos utilizando o ágar ou o phytagel como agentes geleificantes do meio (MACEDO et al., 2003; PEDROSO et al., 2001).

$\mathrm{Na}$ busca de polissacarídeos alternativos e de menor custo, alguns estudos apresentaram bons resultados com o uso de amido de milho ou de mandioca em substituição ao ágar para algumas culturas, principalmente na fase de enraizamento (FERRI \& NACHTIGALL, 1996; FORTES et al., 1994). Entre as vantagens deste polissacarídeo, poder-se-ia citar a facilidade de obtenção e o seu baixo custo quando comparado ao ágar, fatos que poderiam torná-lo um importante aliado na busca da maior eficiência econômica do processo de propagação de plantas em laboratório (ERIG et al., 2004; FERRI et al., 1998; FORTES et al., 1994; PEREIRA \& FORTES, 2003).

Neste contexto, objetivou-se avaliar a influência da consistência do meio, do uso do ágar e sua substituição parcial e total pelo amido de mandioca (fécula) na composição de meios de cultura para o estabelecimento e multiplicação de bananeira e abacaxizeiro.

\section{MATERIAL E MÉTODOS}

O trabalho foi conduzido no Laboratório de Morfogênese e Biologia Molecular da Embrapa Acre, em Rio Branco, AC. Para avaliar a consistência, tipos e combinações de geleificantes alternativos do meio de cultura para a multiplicação in vitro do abacaxizeiro e da bananeira foram realizados dois experimentos, como segue:

\section{Experimento 1 - Influência do ágar e amido de mandioca (fécula) como geleificantes do meio no estabelecimento e multiplicação in vitro do abacaxizeiro}

O experimento foi realizado em duas fases: Estabelecimento das gemas axilares e multiplicação das brotações (subcultivos). O material vegetal utilizado foi obtido de plantas matrizes de abacaxizeiro, cultivares Rio Branco e Quinari, coletadas da coleção de germoplasma da Embrapa Acre. Após a coleta dos talos de brotações do tipo filhote e remoção das folhas, as gemas axilares foram extraídas e submetidas ao processo de assepsia que consistiu da imersão em álcool $70 \%$ por um minuto, hipoclorito de sódio ( $50 \%$ da solução comercial) por quinze minutos e três lavagens em água destilada e esterilizada. Os explantes foram inoculados em tubos de ensaios de $15 \times 150 \mathrm{~mm}$ com $10 \mathrm{~mL}$ de meio de cultura de estabelecimento de abacaxi (MEA), constituído pelos sais e vitaminas de MS (MURASHIGE \& SKOOG, 1962), 2,0 mg.L $\mathrm{L}^{-1}$ de benzilaminopurina (BAP) e 0,25 mg. $\mathrm{L}^{-1}$ de ácido naftalenoacético (ANA). Para avaliação do ágar e amido de mandioca (fécula) como geleificantes, combinados ou não, foram constituídos os seguintes tratamentos: M1: MEA + 5 g.L. $\mathrm{L}^{-1}$ de ágar; M2: MEA + 2,5 g.L $\mathrm{L}^{-1}$ de ágar + 60 g.L $\mathrm{L}^{-1}$ de amido; M3: MEA + 60 g.L. $\mathrm{L}^{-1}$ de amido e M4: MEA + 2,5 g.L. ${ }^{-1}$ de ágar +30 g. $\mathrm{L}^{-1}$ de amido.

$\mathrm{O}$ delineamento experimental utilizado foi inteiramente casualizado, em fatorial 2 x 4, com cinco repetições e cinco explantes por parcela. $\mathrm{O}$ fator cultivar foi testado visando melhor avaliar os tratamentos entre diferentes genótipos e subsidiar a discussão dos resultados alcançados.

Após a inoculação das gemas, o cultivo se desenvolveu por 50 dias, sob temperatura de $25 \pm 2^{\circ} \mathrm{C}$, fotoperíodo de 16 horas e intensidade luminosa de 30 $\mathrm{mmol} \cdot \mathrm{m}^{-2} \cdot \mathrm{s}^{-1}$, quando então foram avaliadas as seguintes variáveis: porcentagem de gemas desenvolvidas, altura das brotações $(\mathrm{cm})$ e número de folhas desenvolvidas.

As brotações desenvolvidas foram imediatamente transferidas para novos meios de cultura com a mesma constituição do MEA, por quatro subcultivos sucessivos em intervalos de 40 dias. As variáveis: altura de brotações, número de folhas e taxa de multiplicação foram avaliadas a cada subcultivo. 
Experimento 2 - Efeitos da consistência física e do agente geleificante do meio na multiplicação in vitro de bananeira

Em frascos de $250 \mathrm{~mL}$ de capacidade com $40 \mathrm{~mL}$ de meio de cultura, brotações de bananeira da cultivar Grand Naine (AAA) já estabelecidas in vitro, foram colocadas para se desenvolverem em meio de cultura de MS, suplementado com 0, 2, 4 e 6 mg.L. $\mathrm{L}^{-1}$ BAP. Para verificar a influência do tipo de agente geleificante (AG) foram constituídos os seguintes tratamentos: MM1: MS + 6 g.L${ }^{1}$ de ágar; MM2: MS + 3 g.L. ${ }^{-1}$ de ágar +30 g.L. $L^{-1}$ de amido de mandioca (fécula); MM3: MS + 60 g.L. $\mathrm{L}^{-1}$ de fécula; MM4: MS líquido.

O experimento seguiu esquema fatorial 4 x 4, com quatro concentrações de BAP e quatro meios de cultura quanto à consistência, totalizando 16 tratamentos. $\mathrm{O}$ delineamento experimental foi inteiramente ao acaso, com quatro repetições e cinco explantes por parcela. Por três subcultivos sucessivos de 30 dias em cada um foi determinada a altura das brotações e a taxa de multiplicação do material em cultivo.

Para ambos os experimentos, o $\mathrm{pH}$ dos meios de cultura foi ajustado para $5,8 \pm 0,1$ antes da autoclavagem, realizada por 15 minutos a $121^{\circ} \mathrm{C}$ e pressão de $1,3 \mathrm{~atm}$. Após a inoculação do material, os experimentos foram mantidos em sala de crescimento nas mesmas condições anteriores.

Para ambos os experimentos, os dados obtidos foram submetidos à análise de variância, sendo as médias comparadas pelo teste de Tukey $(p<5 \%)$. Dados expressos em porcentagem (x) foram transformados segundo arco seno $(\mathrm{x} / 100)^{0,5}$ e os obtidos por contagem $(\mathrm{x})$, transformados segundo $(\mathrm{x}+0,5)^{0,5}$.

\section{RESULTADOS E DISCUSSÃO}

A porcentagem de desenvolvimento das gemas da cultivar Rio Branco foi significativamente superior quando estas foram cultivadas em meios suplementados com amido, combinado ou não com ágar. Além disso, verificou-se também que os meios M2, M3 e M4, geleificados com amido combinado ou não com ágar, apresentaram 94, 85 e $90 \%$ de gemas desenvolvidas, respectivamente, valores estes significativamente superiores aos obtidos no meio M1 $(34,7 \%)$, solidificado somente com ágar (Tabela 1). Constatouse ainda que a cv. Rio Branco apresentou melhores resultados em meios com a adição de amido (M2, M3 e M4).

Para a cv. Quinari, o meio M3 (60 g.L $\mathrm{L}^{-1}$ de fécula) possibilitou a mais alta porcentagem de gemas desenvolvidas, apesar de não diferir estatisticamente do meio M1, contendo apenas o ágar.
Não foram observadas diferenças significativas para as variáveis altura de brotações, número de folhas e aspecto geral das brotações regeneradas entre os meios de cultura testados. Diferenças estatísticas significativas só foram verificadas entre as cultivares testadas, independentemente do meio de cultura utilizado. Na média, a cv. Rio Branco apresentou resultados significativamente superiores à 'Quinari' para as variáveis analisadas (Tabela 2), sugerindo a necessidade de se testar a constituição de novos meios e ajustar protocolos para a multiplicação in vitro da 'Quinari'.

Para a cv. Rio Branco, após quatro subcultivos não foram observadas diferenças significativas para altura e número de folhas/brotação em função do meio de cultura. Diferenças significativas só foram observadas para a variável taxa de multiplicação do material, na qual o meio contendo apenas 60 g. $\mathrm{L}^{-1}$ de amido de mandioca mostrouse estatisticamente similar ao tratamento testemunha M1 (5 g.L. - $^{-1}$ de ágar), com média de 12,6 brotações/explante (Tabela 3). Nos meios M2 e M4, as taxas de multiplicação foram significativamente inferiores às dos meios M1 e M3. Este fato pode ser explicado possivelmente pela menor disponibilidade de nutrientes e reguladores de crescimento do meio para os explantes em razão de sua consistência mais densa. Pinho (2003), avaliando a substituição do ágar por uma mistura de amido (40\% de amido de semente de feijão guandu e $60 \%$ de amido de mandioca) na micropropagação de batata-doce (Ipomoea batatas L.), obteve maior acúmulo de matéria fresca em meio com a mistura de amido a 7\%, como agente geleificante do meio de cultura MS

Em razão da baixa taxa de desenvolvimento das gemas axilares da cv. Quinari, não foi possível avaliar esta cultivar nos subcultivos subseqüentes.

Experimento 2 - Efeitos da consistência e do agente geleificante do meio na multiplicação in vitro de bananeira

Após três subcultivos sucessivos, observou-se que nas concentrações mais altas de BAP a altura das brotações regeneradas foi menor, independente do tipo de meio de cultura e combinação de geleificantes utilizados (Tabela 4). A partir da concentração de $2 \mathrm{mg} . \mathrm{L}^{-1}$ de BAP, não mais se observou diferenças significativas na taxa de multiplicação da cv. Grand Naine. Nesta concentração a taxa média de multiplicação atingiu 4,8:1, embora não tenha diferido estatisticamente dos demais tratamentos. De modo geral, os melhores resultados para taxa de multiplicação foram obtidos com o meio de cultura MM1 geleificado somente com ágar. O cultivo em meio líquido apresentou o 
menor índice de multiplicação, embora para variável altura de brotações o tratamento não tenha diferido estatisticamente dos demais. Entre os meios de cultura, dentro de cada concentração de BAP testada, não foram observadas diferenças significativas para altura de brotações regeneradas (Tabela 4).

Resultados satisfatórios com a utilização de amido de mandioca também foram obtidos por Erig et al. (2004), estudando o efeito de agentes alternativos na multiplicação in vitro de macieira (cv. Galaxy), quando obtiveram melhores resultados para número médio de brotos pela utilização de 6 g.L $\mathrm{L}^{-1}$ de ágar (testemunha) e da combinação de 3 g.. $\mathrm{L}^{-1}$ de ágar +50 g. $\mathrm{L}^{-1}$ de amido de mandioca $(1,82 \mathrm{e}$ 1,79 , respectivamente), atribuindo o bom desempenho obtido com a substituição parcial do ágar à posição em que os explantes permaneceram sobre o meio, que naquele caso mostrou-se pouco consistente, favorecendo que o explante permanecesse na horizontal, posição esta que segundo os autores, é importante para melhorar as taxas de multiplicação do material. Contudo, estes autores observaram péssima aparência dos brotos com a substituição parcial do ágar, o que se refletiu em folhas esbranquiçadas, fato não observado neste trabalho, em virtude provavelmente de se tratar de espécies totalmente diferentes. Já Ferri et al. (1998) verificaram bons resultados para as variáveis número e comprimento de raízes quando se utilizou a substituição parcial do ágar por amido de mandioca durante a fase de enraizamento do porta-enxerto de macieira MM 111, havendo antecipação do surgimento das raízes em dez dias.

TABELA 1 - Porcentagem de explantes com gemas axilares desenvolvidas, cvs. Rio Branco e Quinari, em função do agente geleificante do meio de cultura, após 50 dias de cultivo ${ }^{1}$.

\begin{tabular}{lccccc}
\hline & \multicolumn{4}{c}{ Meio de Cultura } & Média Cvs. \\
\cline { 2 - 5 } \multicolumn{1}{c}{ Cultivares } & M1 & M2 & M3 & M4 & M \\
\hline Rio Branco (RB) & $34,7 \mathrm{aB}$ & $94,0 \mathrm{aA}$ & $85,3 \mathrm{aA}$ & $90,6 \mathrm{aA}$ & $28,7 \mathrm{~b}$ \\
Quinari (QN) & $38,7 \mathrm{aAB}$ & $1,7 \mathrm{bC}$ & $62,6 \mathrm{aA}$ & $11,9 \mathrm{bBC}$ & 51,2 \\
\hline Média (meio de cultura) & 36,7 & 47,8 & 73,9 & \\
\hline
\end{tabular}

${ }^{1}$ Médias seguidas de letras distintas, minúsculas na vertical e maiúsculas na horizontal, diferem entre si pelo teste Tukey a 5\% de probabilidade. M1: MEA + 5g.L-1 de ágar; M2: MEA + 2,5 g.L - $^{-1}$ de ágar +60 g.L $\mathrm{L}^{-1}$ de amido (fécula de mandioca); M3: MEA + 60 g.L.-1 de amido (fécula de mandioca); M4: MEA + 2,5 g.L $\mathrm{L}^{-1}$ de ágar + 30 g.L $\mathrm{L}^{-1}$ de amido (fécula de mandioca). C.V. $38,5 \%$

TABELA 2 - Altura (cm), número de folhas e aspecto de explantes de abacaxi, cvs. Rio Branco (RB) e Quinari (QN), em função da combinação de agentes geleificantes do meio de cultura, após 50 dias de cultivo ${ }^{1}$.

\begin{tabular}{cccccccccc}
\hline & \multicolumn{3}{c}{ Altura $(\mathbf{c m})$} & \multicolumn{3}{c}{$\mathbf{N}^{\circ}$ de folhas } & \multicolumn{3}{c}{ Aspecto Geral } \\
\cline { 2 - 10 } Meios & RB & QN & Média Meio & RB & QN & Média Meio & RB & QN & Média Meio \\
\hline M1 & 0,97 & 0,56 & $0,76 \mathrm{a}$ & 7,5 & 5,8 & $6,65 \mathrm{a}$ & 3,0 & 2,3 & $2,65 \mathrm{a}$ \\
M2 & 0,75 & 0,41 & $0,58 \mathrm{a}$ & 8,3 & 4,1 & $6,2 \mathrm{a}$ & 2,7 & 2,0 & $2,35 \mathrm{a}$ \\
M3 & 1,07 & 0,41 & $0,74 \mathrm{a}$ & 9,2 & 5,2 & $7,2 \mathrm{a}$ & 3,4 & 2,1 & $2,75 \mathrm{a}$ \\
M4 & 0,69 & 0,4 & $0,54 \mathrm{a}$ & 7,9 & 5,6 & $6,75 \mathrm{a}$ & 2,9 & 2,0 & $2,45 \mathrm{a}$ \\
\hline Média Cv. & 0,87A & $0,44 \mathrm{~B}$ & & $8,20 \mathrm{~A}$ & $5,2 \mathrm{~B}$ & & $3,0 \mathrm{~A}$ & $2,1 \mathrm{~B}$ & \\
\hline
\end{tabular}

${ }^{1}$ Médias seguidas de letras distintas, minúsculas na vertical e maiúsculas na horizontal, dentro de cada variável avaliada diferem entre si pelo teste Tukey a 5\% de probabilidade. M1: MEA + 5g.L $\mathrm{L}^{-1}$ de ágar; M2: MEA + 2,5 g.L $\mathrm{L}^{-1}$ de ágar + 60 g.L. $\mathrm{L}^{-1}$ de amido (fécula de mandioca); M3: MEA + 60 g.L.- de amido (fécula de mandioca); M4: MEA + 2,5 g.L${ }^{1}$ de ágar +30 g.L. ${ }^{-1}$ de amido (fécula de mandioca). C.V. $38,5 \%$ 
TABELA 3 - Altura (cm), número de folhas e taxa de multiplicação média de abacaxizeiro, cv. Rio Branco, após quatro subcultivos em meios de cultura com diferentes agentes geleificantes.

\begin{tabular}{cccc}
\hline Meios de cultura & Altura de brotação $(\mathbf{c m})$ & $\mathbf{N}^{\circ}$ de folhas/brotação & Taxa de multiplicação \\
\hline M1 & $1,0 \mathrm{a}$ & $6,9 \mathrm{a}$ & $14,6 \mathrm{a}$ \\
M2 & $1,3 \mathrm{a}$ & $7,0 \mathrm{a}$ & $5,0 \mathrm{~b}$ \\
M3 & $1,0 \mathrm{a}$ & $6,8 \mathrm{a}$ & $12,6 \mathrm{a}$ \\
M4 & $1,1 \mathrm{a}$ & $6,7 \mathrm{a}$ & $9,2 \mathrm{~b}$ \\
\hline
\end{tabular}

Médias seguidas por letras distintas em cada coluna diferem entre si pelo teste Tukey a 5\% de probabilidade.

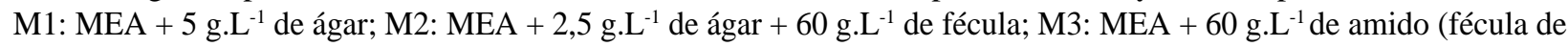
mandioca); M4: MEA + 2,5 g.L $\mathrm{L}^{-1}$ de ágar + 30 g.L. $\mathrm{L}^{-1}$ de amido.

TABELA 4 - Influência da consistência, combinação de gentes geleificantes e concentrações de BAP na altura de brotações $(\mathrm{cm})$ e taxa de multiplicação em banana, cv. Grand Naine, após três subcultivos ${ }^{1}$.

\begin{tabular}{|c|c|c|c|c|c|c|c|c|}
\hline \multirow{3}{*}{$\begin{array}{c}\text { Meio de } \\
\text { multiplicação }\end{array}$} & \multicolumn{4}{|c|}{ Altura de brotação } & \multicolumn{4}{|c|}{ Taxa de multiplicação } \\
\hline & \multicolumn{4}{|c|}{ BAP (mg.L $\left.{ }^{-1}\right)$} & \multicolumn{4}{|c|}{ BAP (mg.L $\left.{ }^{-1}\right)$} \\
\hline & $\mathbf{0}$ & 2 & 4 & 6 & $\mathbf{0}$ & 2 & 4 & 6 \\
\hline MM1 & $4,6 \mathrm{aA}$ & $2,6 \mathrm{aB}$ & $2,5 \mathrm{aB}$ & $2,3 \mathrm{aB}$ & $2,4 \mathrm{aC}$ & $4,8 \mathrm{aA}$ & $3,8 \mathrm{aA}$ & $4,1 \mathrm{aA}$ \\
\hline MM2 & $4,5 \mathrm{abA}$ & $3,5 \mathrm{aB}$ & $2,8 \mathrm{aB}$ & $3,2 \mathrm{aB}$ & $2,5 \mathrm{aB}$ & $3,4 \mathrm{bA}$ & $3,2 \mathrm{aAB}$ & $3,4 \mathrm{abA}$ \\
\hline MM3 & $3,7 \mathrm{abA}$ & $3,0 \mathrm{aAB}$ & $2,5 \mathrm{aB}$ & $2,9 \mathrm{aAB}$ & $2,1 \mathrm{aB}$ & $2,7 \mathrm{bcAB}$ & $2,9 \mathrm{abAB}$ & $3,1 \mathrm{aA}$ \\
\hline MM4 & $3,6 \mathrm{bA}$ & $3,0 \mathrm{aAB}$ & $3,0 \mathrm{aAB}$ & $2,4 \mathrm{aB}$ & $2,1 \mathrm{aA}$ & $2,0 \mathrm{cA}$ & $2,2 \mathrm{bA}$ & $1,7 \mathrm{bA}$ \\
\hline $\mathrm{CV} \%$ & \multicolumn{4}{|c|}{15,7} & \multicolumn{4}{|c|}{7,2} \\
\hline
\end{tabular}

${ }^{1}$ Os dados foram analisados e submetidos à análise de variância e as médias comparadas pelo teste de Tukey. Médias acompanhadas de mesma letra, não diferem estatisticamente entre si a 5\% de probabilidade.

MM1: ágar (6 g.L $\left.\mathrm{L}^{-1}\right)$; MM2: combinação ágar (3 g.L $\left.\mathrm{L}^{-1}\right)$ + fécula de mandioca (30 g.L.-1); MM3: fécula de mandioca $\left(60\right.$ g.L $\left.\mathrm{L}^{-1}\right)$ e; MM4: meio sem solidificante de consistência líquida (estacionário).

\section{CONCLUSÕES}

Gemas axilares de abacaxi, cv. Rio Branco desenvolvem-se satisfatoriamente em meio de cultura suplementado total ou parcialmente com amido de mandioca (fécula);

$\mathrm{O}$ amido de mandioca (fécula) pode ser utilizado isoladamente como geleificante do meio de cultura no estabelecimento de gemas de abacaxi, cv. Quinari, em substituição ao ágar;

Nas condições testadas, a cultivar de abacaxi Rio Branco apresenta respostas de desenvolvimento in vitro superiores à cultivar Quinari;

O uso de fécula de mandioca (60 g. $\left.\mathrm{L}^{-1}\right)$ como geleificante pode substituir o ágar $\left(5 \mathrm{~g} . \mathrm{L}^{-1}\right)$ na multiplicação in vitro da cv. Rio Branco;

Para a bananeira, cv. Grand Naine, o uso isolado ou combinado da fécula com o ágar não proporciona aumento das taxas de multiplicação do material em cultivo;
O cultivo da cv. Grand Naine em meio líquido estacionário não aumenta a taxa de multiplicação in vitro.

\section{REFERÊNCIAS BIBLIOGRÁFICAS}

ERIG, A. C.; SCHUCH, M. W.; SILVA, L. C. da. Multiplicação in vitro de macieira (Malus domestica Borkh.) cv. Galaxy: meio de cultura e agentes solidificantes alternativos. Revista Brasileira de Agrociência, Pelotas, v. 10, n. 3, p. 297-302, jul./set. 2004.

FERRI, V. C.; CENTELLAS, A. Q.; HELBIG, V. E.; FORTES, G. R. de L. Uso de ágar, amido e ácido indolbutírico no enraizamento in vitro do porta enxerto de macieira MM 111. Revista Ciência Rural, Santa Maria, v. 28, n. 4, p. 561$565,1998$. 
FERRI, V. C.; NACHTIGAL, G. R. Influência da sacarose e do ágar na cultura in vitro do clone de pereira Decaisne-6. In: CONGRESSO LATINOAMERICANO DE HORTICUlTURA, 8., 1996, Montevideo. Anais... Montevideo: Associação Latinoamericana de Horticultura, 1996. p. 6.

FORTES, G. R. de L.; CONCEIÇÃO, A. M.; ZANOL, G. Uso do amido comercial como meio solidificante para enraizamento "in vitro" de morangueiro (Fragaria $x$ ananassa). In: CONGRESSO BRASILEIRO DE FRUTICULTURA, 13., 1994, Salvador. Anais... Salvador: Associação Brasileira de Fruticultura, 1994. p. 1113-1114.

FORTES, G. R. L.; PEREIRA, J. E. S. Estabelecimento in vitro da ameixeira cv. América. Revista Brasileira de Fruticultura, Jaboticabal, v. 23, n. 1, p. 183-185, 2001.

GUERRA, M. P.; DAL-VESCO, L. L.; PESCADOR, R.; SCHUELTER, A. R.; NODARI, R. O. Estabelecimento de um protocolo regenerativo para a micropropagação do abacaxizeiro. Pesquisa Agropecuária Brasileira, Brasília, v. 34, n. 9, p. 1557-1563, 1999.

MACEDO, C. E. C.; SILVA, M. G.; NOBREGA, F. S.; MARTINS, C. P.; BARROSO, P. A. V.; ALLOUFA, M. A. I. Concentrações de ANA e BAP na micropropagação de abacaxizeiro L. Merril (Ananas comosus) e no cultivo hidropônico das plântulas obtidas in vitro. Revista Brasileira de Fruticultura, Cruz das Almas, v. 25, n. 3, p. 501-504, 2003.
MENDES, B. M. J.; MENDES, F. J.; TULMANN NETO, A.; DEMÉTRIO, C. G. B.; PUSKE, O. R. Efficacy of banana plantlet production by micropropagation. Pesquisa Agropecuária Brasileira, Brasília, v. 31, n. 12, p. 863867, 1996.

MURASHIGE, T.; SKOOG, F. A revised medium for rapid growth and bio assays with tabacco tissue culture. Physiologia Plantarum, Copenhagen, v. 15, p. 473-497, 1962.

PEDROSO, R. P.; SILVEIRA, D. G.; SILVA, S. O. Concentração de BAP e a eficiência de micropropagação de bananeira tetraplóide (Grupo AAAB). Scientia Agrícola, Piracicaba, v. 58, n. 1, p. 73-78, jan./mar. 2001.

PEREIRA, J. E. S.; BIANCHI, V. J.; DUTRA, L. F.; FORTES, G. R. L. Enraizamento in vitro do morangueiro (Fragaria $x$ ananassa Duchesne) em diferentes concentrações do meio MS. Ciência Rural, Santa Maria, v. 29, n. 1, p. 17-20, 1999.

PEREIRA, J. E. S.; FORTES, G. R. L. Protocolo para a produção de material propagativo de batata em meio líquido. Pesquisa Agropecuária Brasileira, Brasília, v. 38, n. 9, p. 1035-1043, 2003.

PINHO, R. S. Comparação entre ágar e amido como agentes geleificantes na micropropagação de batata doce Ipomoea batatas (L.) Lam. 2003. 88 f. Dissertação (Mestrado em Agronomia/Horticultura) - Universidade Estadual Paulista, Botucatu, 2003. 